\title{
Cultivating Disgust: Prospects and Moral Implications
}

\author{
Charlie Kurth iD \\ Department of Philosophy, Western Michigan University, USA
}

\begin{abstract}
Is disgust morally valuable? The answer to that question turns, in large part, on what we can do to shape disgust for the better. But this cultivation question has received surprisingly little attention in philosophical debates. To address this deficiency, this article examines empirical work on disgust and emotion regulation. This research reveals that while we can exert some control over how we experience disgust, there's little we can do to substantively change it at a more fundamental level. These empirical insights have revisionary implications both for debates about disgust's moral value and for our understanding of agency and moral development more generally.
\end{abstract}

Keywords

disgust, emotion cultivation, emotion regulation, virtue

Debates about disgust's relevance in ethics tend to focus narrowly on the question of whether disgust is morally valuable. ${ }^{1}$ But this overlooks a deeper question about the moral psychology of disgust: is disgust an emotion we can cultivate? To draw out the significance of this cultivation question, notice that a central concern raised by those skeptical of disgust's value focuses on its unreliability: disgust lacks moral value because it's too easy to become disgusted by the morally benign. Clearly, this concern has more bite if there's little we can do to shape errant disgust for the better. But despite all this, questions about our ability to cultivate disgust have received surprisingly little attention. ${ }^{2}$ This suggests that if we're to make progress on questions about disgust's value, we need to look at empirical research on disgust and emotion regulation. When we do this, we see that although one can exert some control over how one experiences disgust, there's little one can do to substantively change it at a deeper level. This empirical insight brings two lessons. First, with regard to debates about disgust's value, we learn that both skeptics and advocates are mistaken: disgust is morally valuable, but not in the ways it's standardly thought to be. Second, recognizing that we can manage - but not change-disgust also has implications for our understanding of virtue and its development: it suggests, with Kantians, that the development of virtue is more a matter of enhancing self-control and less, as Aristotelians propose, a matter of securing psychological harmony among one's feelings, thoughts, and motivations.

Here's the plan. After briefly discussing some terminology, I turn to the question of what disgust is in order to highlight some of disgust's central, but often overlooked features. I then take up the question of whether disgust is morally valuable. As we'll see, looking at the existing debate reveals that questions about disgust's moral value turn on questions about whether disgust can be cultivated. I then draw on empirical findings to vet the three dominant philosophical accounts of emotion cultivation. Building from the lessons gleaned from this investigation, I draw out a set of revisionary conclusions about the moral value of disgust and explore further implications this might have for our understanding of virtue.

\section{Emotions and Emotion Cultivation}

To situate the discussion that follows, here's how I will be understanding emotions like disgust and the process of emotion cultivation. ${ }^{3}$ Taking these in turn, I'll assume that emotions have two general features. First, they're intentional states that can be (in) correct or (un)fitting in virtue of having content that (mis) 
represents the situation at hand. Second, emotions represent the features of one's situation in an evaluatively loaded way. Consider a toy example. To be disgusted by rotting meat is to see it as contaminated - as something to be avoided or rejected. Thus, one's disgust will be fitting just in case the meat really is contaminated. Moreover, to say that an emotion is fitting is to make a distinctive type of evaluation: the situation is as the emotion presents it to be. Thus, one's disgust could be fitting but nonetheless imprudent or immoral (e.g., while disgust is a fitting response to a festering wound, it may be imprudent, even immoral, for a doctor to feel it if that would undermine her ability to care for her patient).

Turning to the second issue-how can we cultivate emotions-I assume that emotions like disgust are at least somewhat malleable: unlike homeostatic mechanisms or reflexes, disgust is something whose functioning we can shape and educate. To further flesh this out, a couple of elaborations will be helpful.

First, I take "emotion cultivation" to refer to our intentional efforts to bring lasting changes to when and how we experience a particular emotion so as to promote certain values. On this front, we find, for example, Aristotelian strategies of habituation, Stoic extirpation therapies, and Kantian techniques of moral education via catechistic instruction. But for what follows, we should also distinguish two distinct, but potentially overlapping, ways in which disgust (say) might be "cultivated." First, we can cultivate disgust by changing the emotion itself. Alternatively, we can shape disgust by changing the nondisgust mechanisms that influence when and how one feels the emotion (e.g., general attentional or cognitive systems, display rules, motor control systems). Putting this another way, if we assume disgust is a disposition, then the first model of cultivation is one that changes the disposition itself; the second model, by contrast, doesn't change the disposition, but rather shapes other cognitive systems that can mask, inhibit, or mimic the operation of the disgust disposition. Moreover, while some cultivation strategies-like Aristotelian habituation - are plausibly understood as seeking to change the disposition, others - like reappraisal — seem better understood as, in the first place, indirect efforts aimed at inhibiting or masking the underlying disposition. So, while there's a sense in which both ways of changing when and how one feels disgust are forms of "cultivation," it's also clear that only the former involves genuine change to the emotion itself - the latter better understood as a kind of "shaping-by-proxy." Of course, exactly how this distinction is drawn will turn on one's theory of emotion-specifically, how one distinguishes between emotions and the nonemotion mechanisms that shape them. What's important for our purposes is that the standard emotion theories all accept this distinction, and so allow that there are two distinct ways of cultivating an emotion like disgust. ${ }^{4}$

Second, since disgust can contribute to a range of instrumental and noninstrumental values, we can assess our ability to cultivate it across various evaluative dimensions. Here, I focus on cultivating disgust in ways that will improve its tendency to promote noninstrumental value - particularly, moral and aretaic value. More specifically, I will argue that disgust can be a fitting response: one's disgust fits when its target is as one's disgust presents it to be. Given this, two questions are of interest. First, what can we do to improve our ability to experience fitting disgust? Second, given that even fitting disgust can cause trouble (because, for instance, the response is too extreme), what can we do to improve our ability to experience it in the right ways - ways conducive to the realization of moral or aretaic value? With this background in hand, we can turn to the details of disgust.

\section{What Is Disgust?}

As a gloss, disgust is an emotion whose characteristic concern is contamination, broadly construed: to be disgusted by something is to see that thing as, in some way, dirty, diseased, corrupting, offensive, or otherwise sickening. Moreover, and importantly for what's to come, though there's debate about how this general notion of contamination should be understood, the general picture is widely endorsed by both advocates and skeptics of disgust's moral value (e.g., Kelly, 2011; Kumar, 2017; W. Miller, 1997; Nussbaum, 2004; Plakias, 2013). To get a better sense of what disgust is, we can say more about its characteristic "inputs" and "outputs."

On the input side, disgust has four noteworthy features. First, though there are common themes in what disgusts us-principally feces, bodily fluids, disease, decay, creepy crawlies, and social/moral norm violations - the range of things that can elicit disgust is strikingly diverse (Kelly, 2011; W. Miller, 1997; Rozin et al., 2008; Tybur et al., 2009). Second, disgust sensitivities have a distinctive developmental trajectory: around 3 years of age, children begin developing sensitivities to "core" or pathogen-oriented elicitors (e.g., feces, rotting food, bodily fluids); later, around age 7, we see sensitivities to "social/moral" elicitors emerging (e.g., food taboos, cheating) (Rozin et al., 2000; Stevenson et al., 2010). This suggests that the development of social/moral disgust is dependent on an individual's conceptual competence in ways that the development of core disgust is not. Third, disgust sensitivities are very easy to develop. As incidents with food poisoning make plain, it often takes just one unfortunate experience with tuna salad gone bad for one to become disgusted by fishy things (Garcia et al., 1974; Oaten et al., 2009). Importantly, the tendency for disgust sensitivities to be quickly acquired is not limited to just edible elicitors. For instance, experimental work reveals that infants display greater aversion behavior (e.g., avoidance, disengagement) to a novel toy when they've seen an adult respond to it with disgust than when the adult responds in a neutral or positive manner (Carver \& Vaccaro, 2007; Hertenstein \& Campos, 2004). Finally, as suggested by the novel toy experiments, developmental research indicates that parents' disgust responses play a significant role in shaping which core and social/moral disgust sensitivities their children acquire (Oaten et al., 2014; Rottman et al., 2018; Stevenson et al., 2010).

Turning to the output side, we find that the diversity of disgust elicitors, and the ease with which they can be developed, is not mirrored in the resulting disgust behaviors. Rather, we find a comparatively narrow and rigid response. The disgust response is narrow in that disgust elicitors - both core and social/moralbring a strikingly uniform tendency to reject, purge, or avoid the object of one's disgust. This pattern of response is accompanied 
by the distinctive "gape" face as well as thoughts of the elicitor as contaminated or polluting (Kelly, 2011; Kumar, 2017; Nussbaum, 2004).

The disgust response is rigid — both synchronically and diachronically. Synchronically, particular disgust episodes are "ballistic" in the following sense: disgust's coordinated pattern of behavior appears quickly and automatically, and, once engaged, the disgust response is very difficult to halt or modify. Paul Rozin's work provides vivid examples: individuals refuse to drink out of a bedpan even though they've been told it was just sterilized, or eat fudge shaped like dog poop despite being informed it's gourmet quality (e.g., Rozin et al., 1986). Importantly, we see this rigid, ballistic response not just with regard to core disgust elicitors, but also morally offensive ones. For instance, individuals refuse to wear a sweater they were told belonged to a murderer and their refusal persists even after being informed that the sweater had been washed (Rozin et al., 1986). But the disgust response is also diachronically rigid. As we'll see at length below, disgust responses are - in comparison to the responses of emotions like fear, anxiety, and anger-difficult to change or modify through (say) repeated exposure or education (Hoyer et al., 2011; Kurth, 2018a, 2018b).

For the discussion that follows, it's worth highlighting what the previous observations suggest about both disgust's underlying cognitive mechanisms and its evolutionary origins. First consider disgust's cognitive architecture. On the input side, we can see that disgust is underwritten by learning mechanisms that allow for the quick (often one-shot) acquisition of disgust sensitivities to a wide range of elicitors-from feces and blood to social/moral violations. By contrast, the mechanisms underlying disgust's outputs are significantly less flexible: not only are they unresponsive to our efforts to modify them in the moment (synchronic rigidity), but they're also resistant to change through exposure and habituation (diachronic rigidity; see Rozin et al., 2000, p. 766, for a similar point). So, and this will be important going forward, while disgust sensitivities are easy to acquire, once developed, they tend to ossify, becoming rigid and entrenched in their effects on our behavior.

These lessons about disgust's cognitive architecture get further support from research examining its evolutionary origins. The general consensus takes disgust to be an evolutionarily shaped defense mechanism: one that was initially oriented toward protecting individuals from biological contaminants, but that has subsequently expanded in scope to also guard against social and moral "contaminants" (e.g., Kelly, 2011; Kumar, 2017; Plakias, 2013; Rozin et al., 2008; Tybur et al., 2013; cf. Rottman et al., 2018). Moreover, this evolutionary account is also thought to explain many of disgust's distinctive features (Kelly, 2011; Kumar, 2017; Plakias, 2013; Tybur et al., 2013). For instance, if disgust began as a pathogen defense mechanism, then that helps explain its distinctive cognitive architecture. Flexible learning mechanisms would allow an individual to guard against the distinctive pathogens of its environment. Similarly, a ballistic and diachronically rigid reject/purge response would not only allow for immediate protection against perceived contaminants, but also help prevent an individual from again eating something that had made them sick-hence the tendency for disgust sensitivities to ossify once acquired. Finally, if disgust began as a contaminant protection mechanism that was co-opted to serve a role in protecting social and moral boundaries, then it's unsurprising that its key features (e.g., "one-shot" learning; ossification; a strong, automatic reject/ purge response) are found not just in core disgust, but also in its social and moral varieties.

A final point. Though controversial, a growing body of research in philosophy and cognitive science suggests there's a distinctly moral form of disgust - the disgust experienced toward hypocrisy, cheating, cruelty, and the like (Giner-Sorolla et al., 2018; Kumar, 2017; Plakias, 2018; cf. Piazza et al., 2018). Support for this comes from various sources. First, there's the contamination connection: behaviors such as hypocrisy and cheating are behaviors that can contaminate beneficial social interactions (Boehm, 2012; Fischbacher et al., 2001; Kumar, 2017; Plakias, 2018). Moreover, while these behaviors are unlike core and taboo-oriented disgust elicitors in that they lack an overt connection to pathogen-related features (decay, bodily fluid), empirical work suggests they are nonetheless conceptually marked as the actions of someone with a deviant, degraded, or otherwise corrupting character (Giner-Sorolla \& Chapman, 2017; Giner-Sorolla et al., 2018; Katzir et al., 2018, Study 2). Finally, behaviors like cruelty and cheating can elicit disgust's characteristic responses, including cleanliness behavior (Jones \& Fitness, 2008, Study 1), reduced consumption (Chan et al., 2014), and reject/purge/avoid efforts (Chapman et al., 2009). ${ }^{5}$

With an understanding of what disgust is in hand, we can turn to questions about its value.

\section{Is Disgust Morally Valuable?}

The above sketch suggests disgust can be a fitting and valuable response to biological contaminants. Disgust toward rotting meat or a decaying corpse is fitting because those things are as disgust presents them to be-namely, putrid, diseased, or otherwise sickening. Moreover, our tendency to react to perceived biological contaminants with disgust's strong reject/purge/avoid response is instrumentally valuable - an effective (if imperfect [Sripada \& Stich, 2004]) defense against poisons, parasites, and disease.

Keeping the distinction between fitting and morally valuable disgust in mind, we can make two further observations. First, disgust is often thought to be a fitting response to social/moral contaminants. It's fitting to be disgusted by things like pedophilia, cheating, and cruelty since these acts are as disgust presents them: sickening, corrupting, and offensive. ${ }^{6}$ Second, and more controversially, given the offensive, corrupting nature of those acts, feelings of revulsion and the associated thoughts that disgust brings can be both morally appropriate and morally valuable.

To draw out the controversy about disgust's moral significance, we can start with the case made by disgust's advocates. First, consider the claim that disgust can be a morally appropriate response. In defense of this, William Miller explains that, 
[T]here are those vices and offenses for which notions of ugliness, smelliness, sliminess readily apply and those for which they do not. Hypocrisy, betrayal, cruelty put us in the swamp of the disgusting, and no other moral sentiment seems as well qualified to express our disapprobation. (1997, p. 205; see also Plakias, 2013)

Pushing further, the (diachronic) rigidity and force of the disgust response can serve as a powerful signal of one's commitment to defending the values threatened by the disgust-eliciting behavior-disgust "marks out moral matters for which we can have no compromise" (W. Miller, 1997, p. 194; see also Kass, 1997; Kumar, 2017). Similarly, the rejection behavior that disgust brings "is often an apt form of punishment for those who cheat, act dishonestly, or exploit others, since these people morally pollute constructive and beneficial social interaction, and thus subvert cooperation" (Kumar, 2017, p. 10; Plakias, 2018). Here it's worth emphasizing that in discussing disgust's moral value, advocates readily acknowledge that the emotion can misfire (e.g., Kumar, 2017; W. Miller, 1997, pp. 197-202; Plakias, 2018). But they nonetheless insist that disgust is a "highly flexible" response, one that "is - or can be — reliably attuned to genuine moral wrongs" (Kumar, 2017, p. 10; see also W. Miller, 1997, pp. 202-203).

We get a very different assessment from disgust skeptics. More specifically, while skeptics seem willing to allow that disgust can be a fitting response in the moral domain (e.g., Kelly, 2011, p. 151; Nussbaum, 2004, pp. 101-106; cf. Knapp, 2003), they deny it's morally valuable. For one, these skeptics maintain that disgust is a hopelessly unreliable detector of moral contaminants: given how flexible disgust's acquisition mechanisms are, it's just too easy for us to become disgusted by the morally benign. Moreover, this flexibility makes disgust too easy to manipulate for nefarious purposes. Not only is history rich in examples of individuals (e.g., women, Jews) being portrayed as having "stock disgust-properties" - being diseased, dirty, or smelly — in order to elicit disgust in their persecutors (Nussbaum, 2004, pp. 107-115), but the targets of these attacks can also come to see themselves as "contaminated" or "disgusting" (Niemi, 2018). Moreover, the strong, ballistic reject/avoid response that disgust brings means that, even when disgust happens to be a fitting response (e.g., it's provoked by hypocritical behavior), it will nonetheless tend to be morally harmful (Kelly, 2011; Kelly \& Morar, 2014; Nussbaum, 2004). In fact, empirical work suggests there's a link between feelings of disgust and dehumanization: individuals who become targets of disgust also tend to be viewed as less than fully human by those who find them disgusting (Harris \& Fiske, 2006; Young \& Saxe, 2011). ${ }^{7}$ Adding to this, skeptics also have little faith in our ability to shape disgust for the better: given the way that disgust portrays its target - as contaminated and contaminatingthey maintain that disgust "will be difficult to contain or aim with any degree of precision" (Kelly \& Morar, 2014, p. 163; see also Nussbaum, 2004, pp. 101-106). In short, disgust's resistance to being corrected or changed means not only that it is "always of dubious reliability" in the moral domain, but also that it will too readily prompt a harmful "demonization and dehumanization" of its targets (Kelly, 2011, pp. 146-152; see also Nussbaum, 2004, Chapter 2).
It's worth highlighting that the skeptics' worry here is less the concern that disgust is inherently lacking in moral value and more the concern that disgust is too unreliable and too likely to do harm. That is, skeptics maintain that disgust lacks moral value because we're unable to effectively change or correct it. Recognizing this is significant, though too often overlooked. It means that debates about disgust's moral value are ultimately debates about disgust's susceptibility to cultivation. But, to date, too little has been done to assess this question: Can disgust be cultivated?

In what follows, I examine three prominent philosophical proposals for cultivating disgust, vetting them against our best empirical understanding of how disgust works. This will reveal that both disgust skeptics and advocates are mistaken about disgust's moral value.

\section{Can Disgust Be Cultivated?}

\section{Education and Enculturation}

The first philosophical proposal for how to cultivate disgust emphasizes learning: the flexibility of disgust's learning mechanisms means we can shape disgust for the better through education and enculturation (Kumar, 2017). But what we've learned about how disgust sensitivities are developed suggests that the flexibility of these learning mechanisms is more likely to be a liability than an asset. For one, there's the ease and speed with which disgust sensitivities can be acquired-recall that we find evidence of "one-shot" learning for a wide range of elicitors, and not just food-based ones. Add to this that there are few restrictions on the types of things that we can become disgusted by. Features like these suggest that what we come to see as a moral contaminant, and so morally disgusting, will be significantly influenced by luck and chance - as much a function of the experiences we just happen to have, as our deliberate efforts to shape what disgusts us. This is all the more so given that, as we saw, developmental findings indicate that feedback from our caretakers is a central driver of which (moral) disgust sensitivities we come to have. Of course, culture can act as a buffer, bringing accumulated insight about what to be disgusted by. But even granting this, the problem remains. The haphazardness of culturally driven food taboos reveals that we can easily become disgusted by things that pose no (biological, social/moral) contamination risk (Sripada \& Stich, 2004). Moreover, even if one's cultural norms are morally sound, one's parents may not be.

Victor Kumar seems sensitive to this issue. To head it off, he suggests that the learning mechanisms responsible for the development of moral disgust sensitivities are different from the oneshot learning mechanisms driving the development of disgust toward core disgust elicitors. But if there's no one-shot learning for moral content, then-contra the above point-there's no reason to think moral disgust cannot be educated. To defend the claim that moral disgust sensitivities don't come by way of core disgust's one-shot learning mechanism, Kumar argues that while there are identifiable adaptive advantages to such a 
learning mechanism for a pathogen-oriented disgust sensitivity (e.g., it's better to be safe than sorry), there's no comparable adaptive advantage for a one-shot learning mechanism for moral violations. As he explains, an "over-sensitivity to cheaters is no more advantageous than under-sensitivity to cheaters" (2017, p. 6).

However, for this response to work, moral disgust sensitivities must come exclusively (or predominantly) from the alternative learning mechanism that Kumar posits. But this suggestion is challenged by experimental findings (noted earlier) indicating that there's one-shot learning for objects like toys that do not have a pathogen connection. Moreover, Kumar's proposal also sits uncomfortably with our understanding of evolution as a conservative process, one that tends to reuse and repurpose mechanisms that already exist even when doing so is (somewhat) suboptimal, all things considered. Thus, on a more plausible evolutionary account, moral disgust sensitivities are the product of two learning mechanisms: the one-shot mechanism inherited from our (evolutionary and developmentally more basic) core disgust, and the (more evolutionarily recent) mechanism Kumar proposes.

Together, these observations suggest our disgust sensitivities - including moral ones - are likely to be shaped, in significant ways, by chance and fortune. If that's right, then we should investigate what can be done to eliminate or mitigate morally problematic disgust sensitivities once they have been acquired.

\section{Aristotelian Habituation and Exposure}

Turning to strategies that might allow us to eliminate or change the disgust sensitivities we happen to develop, one prominent suggestion points to Aristotelian habituation. Justin D'Arms, for example, argues that "since our [emotions] are shaped by experience, it seems we can train them by influencing the experiences to which they are exposed" (2013, p. 9). In the context of disgust, he suggests getting oneself to try foods that one initially finds disgusting (his example: cod milt—or fish sperm) as a way of testing, and so potentially altering, the range of things one is disgusted by. Kumar (2017) supplements this suggestion pointing to research on mothers' responses to the smell of their babies' soiled diapers as evidence of disgust's susceptibility to being shaped through exposure: new parents become less disgusted by the smell of dirty diapers, especially those of their own children (Case et al., 2006). In a similar vein, Paul Rozin (2008) found that medical school students showed reduced disgust sensitivity toward human cadavers after spending several months dissecting them. Together, these observations seem to license optimism about our ability to change (moral) disgust sensitivities for the better.

However, in assessing this habituation proposal, it's worth first noting that while there's a significant amount of empirical work highlighting the effectiveness of exposure as a tool for acquiring disgust sensitivities, we find less work examining the effectiveness of exposure-based techniques to habituate ourselves out of the disgust sensitivities that we've developed. Moreover, the work that has been done does not support the habituation line. Rather, the general trend in this research indicates that disgust sensitivities are "little affected" by efforts to lessen or eliminate them through habituation and exposure (Meunier \& Tolin, 2009; see also Engelhard et al., 2014, Study 1; Mason \& Richardson, 2010; Olatunji et al., 2007). And when we look more closely at the findings that proponents point to, we find they offer-at best - thin support.

First consider Kumar's appeal to the diaper experiment. The fact that the mitigating effect of the diaper exposure on one's disgust was found to be greater with regard to one's own baby suggests it's not the disgust response itself that's changing. Rather, it seems that an independent kin-detection mechanism is being engaged - and is moderating - the disgust response. Putting this into the language of cultivation and shaping by proxy (see: Emotions and Emotion Cultivation), what we appear to have in the diaper case is - pace Kumar - not evidence of the cultivation of disgust via habituation, but rather the shaping of other (kin-detection) mechanisms that then indirectly affect how disgust is experienced. Support for this alternative explanation comes from two sources. First, research indicates that mothers have a general preference for the smell of their own children (Weisfeld et al., 2003) and that parents invest more time and energy in children whose scent they recognize (Dubas et al., 2009). Second, work examining why disgust, in general, tends to be felt less toward "one's own" than toward "others" highlights not one's interaction with the person in question (as the Kumar exposure explanation predicts), but rather that person's status as an in-group member (as suggested by the alternative explanation; Reicher et al., 2016). In light of all this, we should be skeptical of Kumar's claim that the Case et al. experiment is evidence of our ability to use habituation to cultivate disgust.

The force of Rozin's cadaver study is also questionable. For starters, and as Rozin himself notes, while exposure reduced the disgust sensitivity of medical school students to the cold cadavers of the dissection lab, it had no effect on the disgust they felt toward touching the still warm bodies of the recently deceased! Moreover, others argue that these results are likely to generalize in problematic ways: though the disgust one feels toward samesex marriage may diminish after talking with the lesbian couple that moved in next door, it's unlikely to mitigate one's disgust toward, say, marriage between gay men, adoption by gay couples, or the sexual relationships of transgender individuals (Russell \& Giner-Sorolla, 2013). Such fine-grained results suggest exposure should not be thought of as a particularly effective tool for correcting (morally) problematic disgust sensitivities.

We get further cause for concern from work highlighting the persistence of disgust in individuals who have had significant exposure to disgust elicitors that they don't want to be so sensitive to. For instance, experimental work reveals that disgustdriven biases toward homosexuals and minorities persist even among liberal, educated individuals (as measured by self-reports as well as physiological and behavioral responses; Kiebel et al., 2017; see also Devine et al., 2002; Greenwald \& Banaji, 1995). A different line of research on perpetrator disgust - disgust felt by, for example, Nazis as they commit atrocities-also highlights the difficulties of eliminating (or even mitigating) disgust 
through exposure: while the disgust of some perpetrators appears to fade, many others remain disgusted by the awful acts they do (Munch-Jurisic, 2018). ${ }^{8}$ These distinct lines of research are telling both because they complicate the Rozin findings and because they highlight the significant difficulty of eliminating unwanted disgust through habituation.

Taken together, then, this closer look at the empirical work on habituation suggests that even if we grant that exposure can help correct the disgust sensitivities we happen to have acquired, we must also acknowledge that it's likely to bring - at bestonly very narrow, hard-won results.

But the prospects of habituation as a corrective for morally problematic disgust are likely even worse than what the above discussion suggests. To see this, notice that most of the existing research on the effectiveness of exposure-based techniques focuses on core disgust. This is significant in two ways. For starters, some of the most frequently discussed forms of morally problematic disgust concern disgust toward what have been called "bodily" moral violations - actions that run afoul of moral norms about what one can do with one's body (e.g., taboo sexual practices, cannibalism). Moreover, disgust toward bodily moral violations (e.g., homosexuality) appears to be driven less by moral content (e.g., harm, injustice) and more by pathogenrelated features (e.g., bodily fluids, feces; Chapman \& Anderson, 2013; Russell \& Giner-Sorolla, 2013). Now here's the rub: the fact that bodily moral violations incorporate core disgust elicitors suggests that the ineffectiveness of exposure-based techniques for pathogen-oriented core disgust will also plague efforts to use these techniques to correct similarly problematic disgust toward bodily moral violations. So not only does disgust resist correction via habituation, but it's likely to do so for the situations we're most concerned to correct.

This leads to the second issue: while exposure is unlikely to be an effective corrective for bodily moral violations, the proponent of the habituation strategy might nonetheless think it has promise as a way to moderate problematic disgust responses to nonbodily moral violations (e.g., the demonizing of cheaters). After all, such violations lack the independently disgusting content (blood, feces) thought to explain the resistance to exposurebased correction efforts. However, the plausibility of this suggestion is challenged by a pair of empirical findings.

First, disgust toward nonbodily moral violations systematically co-occurs with anger toward those violations. For instance, individuals give nearly identical emotion intensity ratings of disgust and anger in response to photos and descriptions of, for example, hypocritical politicians, racial violence, and instances of exploitation (by contrast, there's no similar overlap in intensity ratings in response to core disgust elicitors; Simpson et al., 2006; see also Rozin et al., 2000). Second, there's a significant body of clinical research showing that excessive anger responses are attenuated through exposure-based methods (Beck \& Fernandez, 1998; Henwood et al., 2015). Taken together, these findings suggest that any behavioral improvements that we see in emotional responses to nonbodily moral violations are likely to be the result of the habituation of anger, not disgust. This conclusion gets further support from work showing that anger and disgust respond very differently to situational cues and new information. For instance, while anger is sensitive to the amount of harm done and the harm-doer's intentions, disgust is not (Russell \& Giner-Sorolla, 2011a, 2011b). What these findings suggest, then, is that habituation works for anger, but not disgust, because only in the case of anger do we have an emotion whose underlying psychological mechanisms make it amenable to correction through exposure and the new information it brings: while disgust responses ossify, anger responses don't.

\section{Copy What Works}

The final approach grants that given what we know about the psychological mechanisms undergirding disgust, attempts to change it via habituation are unlikely to succeed. Consequently, we should look to strategies that have proven effective in shaping psychological processes that are structurally similar to disgust. Here, research on methods for mitigating implicit bias offers a promising model (Kelly \& Morar, 2014). After all, implicit biases, like disgust responses in the moral realm, are socially learned sensitivities that often operate below the level of conscious awareness. Similarly, like disgust, implicit biases are resistant to efforts to directly shape them. Given these structural parallels, what might research on implicit bias mitigation techniques tell us about how we can cultivate (moral) disgust?

Generally speaking, there are two broad strategies for combatting implicit bias (Brownstein, 2015). First, there are changebased strategies which aim to eliminate the underlying beliefs and automatic associations that drive the biases. These techniques seek to undermine, for example, beliefs that White people are smart or associations between "Black" and "bad." Control-based strategies, by contrast, aim to improve an individual's ability to prevent his biased beliefs/associations from affecting his behavior. Here, a common method targets implementation intentions - roughly, the "if, then" rules that guide our actions. Interventions using implementation intentions might aim to, for instance, get an individual to engage a biasmitigating "if Black, then approach" rule rather than a bias-oriented "if Black, then avoid" rule. Though there's overlap between change-based strategies and the exposure-based techniques discussed above (more on this shortly), the control-based strategies that make use of implementation intentions are importantly different: rather than attempting to directly alter or eliminate unwanted beliefs and associations, these methods take an indirect route - one that aims to develop an individual's higher order capacity to recognize problematic situations and (automatically) engage the relevant control-enhancing implementation intention (Gollwitzer \& Schaal, 1998).

Turning to questions of effectiveness, existing research provides us with reasons to be concerned about the use of change-based techniques for disgust. But it also suggests we should be more optimistic about control-based efforts. Let's take these in turn.

The first problem with change-based strategies concerns generalizability: there's good reason to think that the effectiveness of change-based implicit bias strategies will not carry over to (moral) disgust. This is because the most prominent 
change-based interventions-for example, evaluative conditioning (De Houwer, 2011), counter-stereotype exposure (Blair et al., 2001), and increasing intergroup contact (Aberson et al., 2008) - are interventions that seek to eliminate biased beliefs/attitudes through exposure and conditioning. But, as we just saw, (moral) disgust is little affected by exposurebased techniques of this sort.

The second cause for concern is moral. Some of the most effective change-based strategies for combatting (say) racial implicit biases are ones that not only aim to change automatic associations by bolstering the links we make between Black individuals and positive features (e.g., being smart, being friendly), but also seek to bolster associations between White individuals and negative features (e.g., being greedy, being uptight; Lai et al., 2014). This is troubling. It reveals that some of the most effective change-based strategies fit poorly with what becoming a more morally admirable person involves: even if it's true that I'm disgusted by Hispanics, it doesn't follow that, to correct this, I ought to undermine the positive associations I have about Whites.

However, while there are good reasons to be concerned about change-based strategies, the potential of control-based alternatives looks quite different. For instance, recent work by Inge Schweiger Gallo and colleagues has investigated the effectiveness of different implementation intention strategies for disgust (Schweiger Gallo et al., 2009; Schweiger Gallo et al., 2012). More specifically, Schweiger Gallo's team examined whether implementation intentions might positively affect both how one appraises disgust-eliciting stimuli (e.g., blood, bodily fluid) and how one subsequently responds. In both cases, she found that they did. In particular, her team found that implementation intentions targeting appraisal (e.g., if I see blood, I'll take the perspective of a physician) were more effective in reducing how unpleasant one takes a stimulus to be compared to both controls and goal-oriented strategies where one just endorses the aim, for example, of not getting disgusted. Additionally, this work found that implementation intentions targeting response tendencies (e.g., if I see blood, I'll stay calm and relaxed) were also more effective in reducing how repulsed one feels.

It's worth highlighting the robustness of the Schweiger Gallo findings. Not only have her results been replicated by others (e.g., Gomez et al., 2015; Hallam et al., 2015; Heilman et al., 2010; also see the meta-study of Webb et al., 2012), but they also find independent support from work on cognitive behavioral therapy (CBT) as a treatment for obsessive compulsive disorders (OCD). Consider, for instance, research examining the effectiveness of CBT for contamination-oriented OCD - a version of OCD where obsessive thoughts about germs, dirt, and the like lead to compulsive cleaning behavior. This work suggests that contamination-oriented OCD is driven, in part, by one's tendency to feel disgust in response to potential contaminants (Husted et al., 2006; Olatunji et al., 2011, Study 1; Schienle et al., 2003). More importantly, the associated compulsive behavior can be reduced through disgust-targeting CBTspecifically, strategies focused on bolstering one's ability to both recognize potential disgust-eliciting contaminants and engage techniques aimed at blocking the feelings of disgust that would otherwise result (McKay, 2006; Olatunji et al., 2011, Study 2). As with Schweiger Gallo's implementation intention techniques, this CBT-based strategy does not attempt to directly change disgust via exposure. Rather, it seeks to enhance one's (higher order) ability to control how one responds to what one finds disgusting.

In sum, the previous observations about implicit bias regulation strategies suggest they can be helpful as tools for cultivating (moral) disgust. But we've also seen that there are important differences in the effectiveness and moral acceptability of particular strategies - on both fronts, control-based strategies are better.

\section{Lessons Learned}

Bringing this discussion of emotion cultivation strategies to a close, we can extract two general lessons from the discussion so far. First, the flexibility of disgust's learning mechanism suggests that it's possible to cultivate morally appropriate disgust. However, the ease with which disgust sensitivities can be developed and the degree of influence that caretakers have over that process reveal that the disgust sensitivities one happens to acquire will be shaped - in significant ways - by luck and chance. Second, the rigidity of the disgust responses - in particular, the tendency for disgust sensitivities to ossify once acquiredexplains why it's so difficult to directly change or correct them. Moreover, given that this rigidity appears to be a product of disgust's underlying cognitive architecture, we should expect that indirect efforts to shape disgust for the better will prove more effective. The results from work on disgust-focused implementation intentions and CBT support this prediction. Moreover, while it's important to recognize that research on the effectiveness of disgust-focused implementation intentions is still in its early stages, the positive results we find across different labs and using different experimental paradigms stand in contrast to the (at best) equivocal findings regarding the effectiveness of habituation, exposure, and related change-oriented techniques. Putting all this in the language of introduced at the beginning of the paper, while the prospects for the cultivation of disgust are dim, the potential for shaping by proxy looks more promising.

\section{Reassessing Disgust's Moral Value: Two Implications}

Learning about how disgust responds to our efforts to shape it has two implications for our understanding of disgust's moral value. The first concerns what we should do to address morally problematic disgust. Given the structural and moral concerns uncovered above, efforts to shape disgust for the better should emphasize control-based strategies. That is, our efforts should focus not on (direct) attempts to change what we are disgusted by, but rather on (indirect) efforts to enhance self-control. To see what this might amount to, consider someone who is strongly disgusted by members of a particular minority group (the Gs). As suggested above, such an individual would be best served to adopt implementation intentions aimed at helping 
him both reduce his tendency to see members of this group as disgusting (e.g., if I see Gs, I'll adopt the perspective of Martin Luther King Jr.) and moderate his resulting reject/ avoid response (e.g., if I see Gs, I'll relax and be friendly). Importantly, such an effort does not amount to an attempt to directly change his disgust response. Rather, it's a strategy whereby he develops a higher order capacity to recognize situations where his disgust response may misfire so that he may engage implementation intentions that will better enable him to control his disgust. In short, when it comes to "cultivating" disgust, our focus should be on shaping by proxy. ${ }^{9}$

The second implication builds from here. The above observations challenge the accounts of disgust's moral value that we get from both skeptics and advocates. For starters, the disgust skeptic's pessimism about our ability to shape our disgust response for the better is overblown. Though the skeptic is correct that full-fledged change is unlikely once morally problematic disgust sensitivities have been acquired, she's mistaken in two ways. First, the skeptic is mistaken in thinking that there's little we can do to mitigate the unreliability and harmfulness of our disgust response. While there may be little one can do to directly improve reliability, the earlier discussion of the individual disgusted by the Gs highlights how one can indirectly correct problematic disgust. Similarly, implementation intentions geared toward moderating disgust's strong reject/purge response can also help lessen the harm that one's disgust response can bring. Second, the skeptic is wrong to think disgust lacks moral value. As we've seen, implementation intentions can help mitigate both how disgusting one appraises something to be and how strongly one responds to what one finds disgusting (more on this below). But this means that implementation intentions can allow us to better realize the moral value of fitting disgust felt in the face of hypocrisy, cruelty, pedophilia, and the like.

The lessons we've learned about disgust also cause trouble for advocates of its moral value. The advocates are correct both that disgust sensitizes us to a distinctive type of moral wrong - the polluting practices and personalities that contaminate beneficial social interactions - and that disgust's strong reject/purge reaction can be a morally appropriate response to these wrongs. But advocates are mistaken on three fronts. First, their confidence that disgust will naturally tend to track what's morally contaminating is misplaced. As we've seen, the permissiveness and speed of disgust's learning mechanisms, as well as the significant influence caretakers have, mean that chance plays a large role in determining what moral disgust sensitivities one happens to acquire. Second, they overestimate disgust's malleability. While disgust sensitivities are easily shaped, they resist change once acquired. Finally, in emphasizing education and habituation, advocates make the wrong recommendation for how to correct problematic disgust.

Stepping back, the errors of the skeptics and advocates have a common cause: a mistaken account of the moral psychology of disgust. In particular, both sides are wrong about what we can and cannot do to shape disgust for the better.

\section{Further Implications: Virtue and Its Development}

I close on a more speculative note. Appreciating the limits of our ability to shape (moral) disgust may have implications for our understanding of human virtue and its development. In short, what we've learned suggests - in line with a broadly Kantian picture - that becoming virtuous is more a matter of enhancing self-control and less, as Aristotelians propose, a matter of securing psychological harmony. To draw this out, I begin by presenting the Aristotelian picture and the trouble that the account of disgust developed so far seems to bring. While this sketch will gloss over much of the richness in the Aristotelian proposal, it will nonetheless allow us to see how the above lessons about disgust suggest that virtue and its development might be better understood in Kantian terms.

To begin, contemporary Aristotelians build from the familiar distinction between virtuous action and merely continent (or encratic) action. According to these Aristotelians, virtuous actions are ones where one's emotions are in harmony with one's motivations (e.g., one helps from a feeling of sympathy). By contrast, with mere continence, one does the right thing despite feeling contrary emotions (e.g., one provides assistance but resents having to do it). Importantly, while Aristotelians see value in encratic actions, they also see them as less valuable than virtuous ones (e.g., Annas, 2011, p. 67; Foot, 1978; Hursthouse, 2001).

The Aristotelians' rendering of virtue in terms of attunement is then combined with a moral psychology that emphasizes the malleability of emotion. As Julia Annas explains, on the Aristotelian account, our "emotions can be so educated by our developing reason that they become wholly transformed" (2011, p. 68, emphasis added; Sherman, 1989, Chapter 5; cf. Hursthouse, 2001, pp. 115-116). So understood, moral development is a process whereby one cultivates one's emotions so that they accord with one's judgments and actions. A corollary to this is that virtuous individuals are more admirable because they have substantively shaped-transformed-their emotions so that they're felt at the right time and in the right way.

From these observations, we can extract two Aristotelian theses about the place of emotion in virtue. First, there's a normative claim about moral development: moral development should aim to transform the learner's emotions so that they are felt at the right time and in the right way. Second, there's a conceptual claim about the nature of virtue: an action is (fully) virtuous just in case and because one's feelings and motivations to do the right thing form a unified, harmonious whole. Importantly, what unifies these two claims is the Aristotelians' moral psychology - specifically, their claim about the malleability of emotion.

However, given what we've learned about disgust, we should be wary of the Aristotelians' account. While emotions like anger, fear, and compassion may be malleable in the manner that the Aristotelians' moral psychology presumes, this is not the case for emotions like disgust. As we've seen, the tendency for our disgust sensitivities to ossify once acquired means that there's little we 
can do to substantively change - much less "wholly transform"what we're disgusted by. ${ }^{10}$ But if the Aristotelians' moral psychology is mistaken, then this should raise doubts about their larger account of virtue. The trouble is most acute for their thesis about moral development — it, after all, specifically prescribes efforts to transform emotions. But as we've seen, the Aristotelians' moral psychology plays a central role in supporting their overall account. So, we should also be wary of their account of virtue. If there's little we can do to change or transform problematic disgust responses, then why accept the Aristotelians' universal claim that virtue consists in harmonious attunement?

Of course, Aristotelians are not without avenues of reply. Most obviously, they could appeal to the familiar claim that virtue is rare. If it is, then virtue just may not be attainable for those who, because of bad luck or insufficient effort, have developed problematic disgust sensitivities. However, since Aristotelians are divided on the plausibility of the rarity thesis, this strategy will have limited appeal. ${ }^{11}$ But more significantly, this line of reply also misconstrues the challenge that disgust presents. While we should acknowledge the role that luck and effort play in the development of virtue, that's not what is at issue here. Rather, the issue concerns the adequacy of the Aristotelians' moral psychology: given what we've learned about emotions like disgust, human emotions do not appear to have the homogeneity that the Aristotelian account presumes and requires. And since the claim that emotions are homogeneous helps substantiate the Aristotelians' larger proposal, the troubles with their moral psychology carry over to their overall account of virtue.

Clearly, more work is needed to assess the challenge that disgust brings to Aristotelian accounts of virtue. Rather than taking that up, I want to see what a broadly Kantian alternative to the Aristotelian account might look like.

In contrast with Aristotelians', the Kantian moral psychology denies that we are able to thoroughly (re)educate or wholly transform our emotions (Baxley, 2010; Cureton \& Hill, 2015; Surprenant, 2014). Moreover, the Kantians' more modest moral psychology also informs their associated account of virtue and its development. On this account, human virtue is not understood in terms of Aristotelian harmony, but rather self-control. In particular, virtue is understood as the motivational strength to overcome contrary emotions and inclinations in order to do the right thing. Moral development, then, is a process where one learns how to "comba[t] natural impulses sufficiently to be able to master them when a situation comes up in which they threaten morality" (Kant, 1797/1996, pp. 485, 598; see also Baxley, 2010; Surprenant, 2014). What, exactly, this learning process involves is an open (empirical) question. But our earlier discussion suggests it should focus on enhancing one's higher order capacity to (a) recognize situations where contrary emotions will be elicited and (b) engage the appropriate response prevention strategy.

With this sketch in hand, we can see that a Kantian moral psychology fits better with empirical findings regarding the limits of our ability to directly change emotions like disgust. In so doing, it provides the foundation for an alternative account of virtue and its development. On this Kantian account, virtuous action is less a matter of emotional attunement and more a function of a unique form of motivational self-control. More specifically, an action is (fully) virtuous just in case and because it manifests one's ability to overcome contrary emotions and inclinations in order to do the right thing. This rendering of virtue then leads to a normative claim about what moral development ought to look like-specifically, the central aim of moral education should be the development of the moral understanding and discipline one needs to manifest the self-control characteristic of virtue.

More, of course, is needed to flesh out the contrast between these Kantian and Aristotelian accounts. But as a first step toward seeing the appeal of the Kantian proposal, consider what it suggests about our earlier example of the individual who is disgusted by Gs. Fleshing out the details, suppose this individual's disgust is the result of an unfortunate upbringing. Suppose further that once he recognizes that his disgust is morally problematic, he takes steps to address the issue (e.g., engaging implementation intentions of the sort described in see: Reassessing Disgust's Moral Value: Two Implications). So, though he hasn't transformed the disgust he feels toward Gs, he can now effectively control it. On the Kantian account, such an individual could be fully virtuous.

Aristotelians will find this implausible - how could someone be virtuous despite being subject to racist emotional reactions? After all, such an individual's lingering disgust prevents him from seeing Gs as full moral agents: to be disgusted by Gs just is to see Gs as lesser agents. So, while the individual's efforts to control his disgust may have value, they do not make him virtuous. Rather, he "remain[s] morally inferior" (e.g., Hursthouse, 2001, pp. 116-117; also see Annas, 2011; Foot, 1978). ${ }^{12}$

But this objection may be too quick. Contra the Aristotelian retort, what we've learned about the psychology of disgust suggests that disgust does not prevent an individual of the sort we're considering from being able to see Gs as full moral agents. After all, as the discussion of implementation intentions revealed, in order for such an individual to have reformed in the ways that he did, he needed to develop not just a higher order awareness of the problematic nature of his disgust toward Gs, but also the self-control to reject and subdue disgust's impact on his perceptions and actions. But to do that just is to recognize, and even embrace, the full personhood of Gs. So, while more needs to be said to develop and defend this proposal, we can see that-backed with a rich, empirically informed moral psychology - the Kantian proposal has much to offer.

\section{Conclusion}

Thinking about disgust with an eye to what empirical work tells us about our ability to shape and correct it brings unexpected insights. First, with regard to debates about disgust's value, we learn that both skeptics and advocates are mistaken: disgust is morally valuable, but not in the ways it's standardly thought to be. Second, recognizing that we can control, but not change, disgust also has implications for our understanding of human virtue and its development-inviting us to think more seriously about a broadly Kantian approach. But the discussion here also suggests that there are important differences in the moral 
psychology of emotions: while emotions like disgust resist our efforts to shape them for the better, other emotions-like anger and fear - are more susceptible to cultivation. Thus, if we are to develop an accurate account of emotions' value and relevance for virtuous agency, we need to look closely at psychological mechanisms that undergird emotional life.

\section{Declaration of Conflicting Interests}

The author(s) declared no potential conflicts of interest with respect to the research, authorship, and/or publication of this article.

\section{Funding}

The author(s) received no financial support for the research, authorship, and/or publication of this article.

\section{ORCID iD}

Charlie Kurth (iD) https://orcid.org/0000-0002-2836-9163

\section{Notes}

1 See, for instance, Kass (1997); Kelly (2011); Kelly and Morar (2014); Knapp (2003); Kumar (2017); W. Miller (1997); Nussbaum (2004); Plakias (2013).

2 Kelly and Morar (2014) is an exception.

3 I take this picture to be generally (but not universally) accepted among emotion theorists in general, as well as those whose accounts I will be discussing.

4 The psychological literature tends to focus on emotion regulation, not cultivation (e.g., Gross, 2015). The difference between regulation and cultivation is murky. But one way to understand it is that, in contrast to cultivation, regulation typically refers to our unconscious efforts to affect short-term changes in when/how we experience an emotion. This allows, of course, that regulation techniques (e.g., attention redirection, response modulation) can be enlisted as part of one's efforts to affect long-term change via cultivation.

5 Given the argument to come, it's worth noting that the claim that moral disgust is a form of disgust appears to be accepted by both advocates (e.g., Kumar, 2017; W. Miller, 1997) and skeptics (e.g., Kelly, 2018; Nussbaum, 2004).

6 This point is endorsed by both advocates and (some) skeptics (e.g., Kelly, 2011, p. 151; Kumar, 2017; W. Miller, 1997; Nussbaum, 2004, pp. 102-103; Plakias, 2018; cf. Knapp, 2003).

7 It's important to note that this empirical work is merely correlationalas such, it does not determine whether disgust causes dehumanization or vice versa (Kumar, 2017).

8 There's reason to be cautious about the apparent "success" that some perpetrators appear to have in ridding themselves of their disgust: not only does most of the evidence come from self-reports, but the perpetrators also often have strong motivations for denying that they felt disgusted by what they did (e.g., in order to be seen as a good Nazi).

9 Of note, work on implicit bias suggests that efforts to improve our control over morally problematic disgust might be enhanced if approached institutionally - for example, the use of organizational structures or protocols that raise individuals' awareness of how disgust enters into hiring and admissions decisions (Payne \& Vuletich, 2018).

10 Importantly, disgust does not seem to be unique in this respecthatred, for instance, also appears resistant to change (Allport, 1979; Brudholm, 2010).

11 For defenders of rarity, see Hursthouse (2001); C. Miller (2014); for opposition, see Annas (2011); Stichter (2018).

12 It's worth noting that the claim that disgust presents its target as a lesser moral agent is quite controversial (Kumar, 2017; Plakias, 2013).

\section{References}

Aberson, C., Porter, M., \& Gaffney, A. (2008). Friendships predict Hispanic student's implicit attitudes toward Whites relative to African Americans. Hispanic Journal of Behavioral Sciences, 30, 544-556.

Allport, G. (1979). The nature of prejudice. Perseus Books.

Annas, J. (2011). Intelligent virtue. Oxford University Press.

Baxley, A. M. (2010). Kant's theory of virtue. Cambridge University Press.

Beck, R., \& Fernandez, E. (1998). Cognitive-behavioral therapy in the treatment of anger: A meta-analysis. Cognitive Therapy and Research, 22(1), 63-74.

Blair, I., Ma, J., \& Lenton, A. (2001). Imagining stereotypes away. Journal of Personality and Social Psychology, 81(5), 828-841.

Boehm, C. (2012). Moral origins: The evolution of virtue, altruism, and shame. Soft Skull Press.

Brownstein, M. (2015). Implicit bias. In E. Zalta (Ed.), The Stanford encyclopedia of philosophy (Spring 2017 ed.). Stanford University. https:// plato.stanford.edu/archives/spr2017/entries/implicit-bias/

Brudholm, T. (2010). Hatred as an attitude. Philosophical Papers, 39, 289-313.

Carver, L., \& Vaccaro, B. (2007). 12-month-old infants allocate increased neural resources to stimuli associated with negative adult emotion. Developmental Psychology, 43(1), 54-69.

Case, T., Repacholi, B., \& Stevenson, R. (2006). My baby doesn't smell as bad as yours. Evolution and Human Behavior, 27(5), 357-365.

Chan, C., van Boven, L., Andrade, E. B., \& Ariely, D. (2014). Moral violations reduce oral consumption. Journal of Consumer Psychology, 24(3), 381-386.

Chapman, H., \& Anderson, A. (2013). Things rank and gross in nature. Psychological Bulletin, 139, 300-327.

Chapman, H. A., Kim, D. A., Susskind, J. M., \& Anderson, A. K. (2009). In bad taste: Evidence for the oral origins of moral disgust. Science, $323,1222-1226$.

Cureton, A., \& Hill, T. (2015). Kant on virtue and the virtues. In N. Snow (Ed.), Cultivating virtue (pp. 87-110). Oxford University Press.

D'Arms, J. (2013). Value and the regulation of the sentiments. Philosophical Studies, 163, 3-13.

De Houwer, J. (2011). Evaluative conditioning. In T. Schachtman \& S. Reilly (Eds.), Associative learning and conditioning theory (pp. 399417). Oxford University Press.

Devine, P. G., Plant, E. A., Amodio, D. M., Harmon-Jones, E., \& Vance, S. L. (2002). The regulation of explicit and implicit race bias. Journal of Personality and Social Psychology, 82(5), 835-848.

Dubas, J., Heijkoop, M., \& van Aken, M. (2009). A preliminary investigation of parent-progeny olfactory recognition and parental investment. Human Nature, 20(1), 80-92.

Engelhard, I., Leer, A., Lange, E., \& Olatunji, B. (2014). Shaking that icky feeling. Behavior Therapy, 45(5), 708-719.

Fischbacher, U., Gächter, S., \& Fehr, E. (2001). Are people conditionally cooperative? Economics Letters, 71(3), 397-404.

Foot, P. (1978). Virtues and vices. University of California Press.

Garcia, J., Hankins, W., \& Rusiniak, K. (1974). Behavioral regulation of the milieu interne in man and rat. Science, 185, 824-831.

Giner-Sorolla, R., \& Chapman, H. A. (2017). Beyond purity: Moral disgust toward bad character. Psychological Science, 28(1), 80-91.

Giner-Sorolla, R., Kupfer, T., \& Sabo, J. (2018). What makes moral disgust special? Advances in Experimental Social Psychology, 57, 223-289.

Gollwitzer, P., \& Schaal, B. (1998). Metacognition in action: The importance of implementation intentions. Personality and Social Psychology Review, 2, 124-136.

Gomez, P., Scholz, U., \& Danuser, B. (2015). The down-regulation of disgust by implementation intentions. Applied Psychophysiology and Biofeedback, 40, 95-106.

Greenwald, A., \& Banaji, M. (1995). Implicit social cognition: Attitudes, self-esteem, and stereotypes. Psychological Review, 102, 4-27. 
Gross, J. (2015). Emotion regulation: Current status and future prospects. Psychological Inquiry, 26, 1-26.

Hallam, G., Webb, T., Sheeran, P., Miles, E., Wilkinson, I., Hunter, M. D., Barker, A. T., Woodruff, P. W. R., Totterdell, P., Lindquist, K. A., \& Farrow, T. F. D. (2015). The neural correlates of emotion regulation by implementation intentions. PloS One, 10(3), Article e 0119500.

Harris, L., \& Fiske, S. (2006). Dehumanizing the lowest of the low. Psychological Science, 17(10), 847-853.

Heilman, R. M., Crişan, L. G., Houser, D., Miclea, M., \& Miu, A. C. (2010). Emotion regulation and decision making under risk and uncertainty. Emotion, 10(2), 257-265.

Henwood, K., Chou, S., \& Browne, K. (2015). A systematic review and meta-analysis on the effectiveness of CBT informed anger management. Aggression and Violent Behavior, 25, 280-292.

Hertenstein, M., \& Campos, J. (2004). The retention effects of an adult's emotional displays on infant behavior. Child Development, 75, 595-613.

Hoyer, J., van der Heiden, C., \& Portman, M. E. (2011). Psychotherapy for generalized anxiety disorder. Psychiatric Annals, 41, 87-94.

Hursthouse, R. (2001). On virtue ethics. Oxford University Press.

Husted, D., Shapira, N., \& Goodman, W. (2006). The neurocircuitry of obsessive-compulsive disorder and disgust. Progress in Neuro-psychopharmacology and Biological Psychiatry, 30, 389-399.

Jones, A., \& Fitness, J. (2008). Moral hypervigilance: The influence of disgust sensitivity in the moral domain. Emotion, 8(5), 613-627.

Kant, I. (1996). Metaphysics of morals. In M. Gregor \& A. Wood (Eds.), Practical philosophy (pp. 353-604). Cambridge University Press. (Original work published 1797)

Kass, L. (1997, June 2). The wisdom of repugnance. The New Republic, pp. $17-26$.

Katzir, M., Hoffmann, M., \& Liberman, N. (2018). Disgust as an essentialist emotion that signals nonviolent outgrouping with potentially low social costs. Emotion, 19, 841-862.

Kelly, D. (2011). Yuck! MIT Press.

Kelly, D. (2018). Cast in a bad light or reflected in a dark mirror? In N. Strohminger \& V. Kumar (Eds.), The moral psychology of disgust (pp. 171-194). Rowman \& Littlefield.

Kelly, D., \& Morar, N. (2014). Against the yuck factor. Utilitas, 26, $153-177$

Kiebel, E., McFadden, S., \& Herbstrith, J. (2017). Disgusted but not afraid. The Journal of Social Psychology, 157, 263-278.

Knapp, C. (2003). De-moralizing disgustingness. Philosophy and Phenomenological Research, 66(2), 253-278.

Kumar, V. (2017). Foul behavior. Philosopher's Imprint, 17(15), 1-17.

Kurth, C. (2018a). Anxiety: A case study on the value of negative emotions. In C. Tappolet, F. Teroni, \& A. Konzelmann (Eds.), Shadows of the soul: Philosophical perspectives on negative emotions (pp. 95-104). Routledge.

Kurth, C. (2018b). The anxious mind. MIT Press.

Lai, C. K., Marini, M., Lehr, S. A., Cerruti, C., Shin, J. E. L., Joy-Gaba, J. A., Ho, A. K., Teachman, B. A., Wojcik, S. P., Koleva, S. P., Frazier, R. S., Heiphetz, L., Chen, E. E., Turner, R. N., Haidt, J., Kesebir, S., Hawkins, C. B., Schaefer, H. S., Rubichi, S., . . Nosek, B. A. (2014). Reducing implicit racial preferences. Journal of Experimental Psychology: General, 143(4), 1765-1785.

Mason, E., \& Richardson, R. (2010). Looking beyond fear: The extinction of other emotions implicated in anxiety disorders. Journal of Anxiety Disorders, 24, 63-70.

McKay, D. (2006). Treating disgust reactions in contamination-based obsessive-compulsive disorder. Journal of Behavior Therapy and Experimental Psychiatry, 37, 53-59.

Miller, C. (2014). The problem of character. In S. van Hooft (Ed.), The handbook of virtue ethics (pp. 418-429). Cambridge University Press.

Miller, W. (1997). The anatomy of disgust. Cambridge University Press.
Meunier, S., \& Tolin, D. (2009). The treatment of disgust. In B. Olatunji \& D. McKay (Eds.), Disgust and its disorders (pp. 271-283). American Psychological Association.

Munch-Jurisic, D. (2018). Perpetrator disgust: A morally destructive emotion. In T. Brudholm \& J. Lang (Eds.), Emotions and mass atrocity (pp. 142-161). Cambridge University Press.

Niemi, L. (2018). The morally relevant consequences of disgust in the context of sexual assault. In N. Strohminger \& V. Kumar (Eds.), The moral psychology of disgust (pp. 103-120). Rowman \& Littlefield.

Nussbaum, M. (2004). Hiding from humanity: Disgust, shame, and the law. Princeton University Press.

Oaten, M., Stevenson, R., \& Case, T. (2009). Disgust as a disease avoidance mechanism. Psychological Bulletin, 135, 303-321.

Oaten, M., Stevenson, R. J., Wagland, P., Case, T. I., \& Repacholi, B. M. (2014). Parent-child transmission of disgust and hand hygiene. Psychological Record, 64(4), 803-811.

Olatunji, B. O., Smits, J. A., Connolly, K., Willems, J., \& Lohr, J. M. (2007). Examination of the decline in fear and disgust during exposure to threat-relevant stimuli in blood-injection-injury phobia. Journal of Anxiety Disorders, 21(3), 445-455.

Olatunji, B. O., Tart, C. D., Ciesielski, B. G., McGrath, P. B., \& Smits, J. A. (2011). Specificity of disgust vulnerability in the distinction and treatment of OCD. Journal of Psychiatric Research, 45(9), $1236-1242$.

Payne, B. K., \& Vuletich, H. A. (2018). Policy insights from advances in implicit bias research. Policy Insights from the Behavioral and Brain Sciences, 5(1), 49-56.

Piazza, J. R., Landy, J., Chakroff, A., Young, L., \& Wasserman, E. (2018). What disgust does and does not do for moral cognition. In N. Strohminger \& V. Kumar (Eds.), The moral psychology of disgust (pp. 53-82). Rowman \& Littlefield.

Plakias, A. (2013). The good and the gross. Ethical Theory and Moral Practice, 16, 261-278.

Plakias, A. (2018). The response model of moral disgust. Synthese, 195(12), 5453-5472.

Reicher, S. D., Templeton, A., Neville, F., Ferrari, L., \& Drury, J. (2016). Core disgust is attenuated by ingroup relations. Proceedings of the National Academy of Sciences, 113, 2631-2635.

Rottman, J., DeJesus, J., \& Gerdin, E. (2018). The social origins of disgust. In N. Strohminger \& V. Kumar (Eds.), The moral psychology of disgust (pp. 27-52). Rowman \& Littlefield.

Rozin, P. (2008). Hedonic "adaptation": Specific habituation to disgust/ death elicitors as a result of dissecting a cadaver. Judgment and Decision Making, 3(2), 191-194.

Rozin, P., Haidt, J., \& McCauley, C. (2008). Disgust. In M. Lewis, J. Haviland-Jones, \& L. Barrett (Eds.), Handbook of emotions (pp. 757-776). Guilford Press.

Rozin, P., Lowery, L., Imada, S., \& Haidt, J. (2000). The CAD triad hypothesis. Journal of Personality and Social Psychology, 76(4), 574-586.

Rozin, P., Millman, L., \& Nemeroff, C. (1986). Operation of the laws of sympathetic magic in disgust and other domains. Journal of Personality and Social Psychology, 50(4), 703-712.

Russell, P., \& Giner-Sorolla, R. (2011a). Moral anger, but not moral disgust, responds to intentionality. Emotion, 11, 233-240.

Russell, P., \& Giner-Sorolla, R. (2011b). Moral anger is more flexible than moral disgust. Social Psychological and Personality Science, 2, 360-364.

Russell, P., \& Giner-Sorolla, R. (2013). Bodily moral disgust. Psychological Bulletin, 139(2), 328-351.

Schienle, A., Stark, R., Walter, B., \& Vaitl, D. (2003). The connection between disgust sensitivity and blood-related fears, faintness symptoms, and obsessive-compulsiveness in a non-clinical sample. Anxiety, Stress, and Coping, 16(2), 185-193. 
Schweiger Gallo, I., Keil, A., McCulloch, K. C., Rockstroh, B., \& Gollwitzer, P. M. (2009). Strategic automation of emotion regulation. Journal of Personality and Social Psychology, 96(1), 11-31.

Schweiger Gallo, I., McCulloch, K. C., \& Gollwitzer, P. M. (2012). Differential effects of various types of implementation intentions on the regulation of disgust. Social Cognition, 30(1), 1-17.

Sherman, N. (1989). The fabric of character. Oxford University Press.

Simpson, J., Carter, S., Anthony, S., \& Overton, P. (2006). Is disgust a homogeneous emotion? Motivation and Emotion, 30, 31-41.

Sripada, C., \& Stich, S. (2004). Evolution, culture, and the irrationality of the emotions. In D. Evans \& P. Cruse (Eds.), Emotion, evolution and rationality (pp. 133-158). Oxford University Press.

Stevenson, R. J., Oaten, M. J., Case, T. I., Repacholi, B. M., \& Wagland, P. (2010). Children's response to adult disgust elicitors. Developmental Psychology, 46(1), 165-177.
Stichter, M. (2018). The skillfulness of virtue: Improving our moral and epistemic lives. Cambridge University Press.

Surprenant, C. (2014). Kant and the cultivation of virtue. Routledge.

Tybur, J. M., Lieberman, D., \& Griskevicius, V. (2009). Microbes, mating, and morality: Individual differences in the three functional domains of disgust. Journal of Personality and Social Psychology, 97, 103-122.

Tybur, J. M., Lieberman, D., Kurzban, R., \& DeScioli, P. (2013). Disgust: Evolved function and structure. Psychological Review, 120(1), 65-84.

Webb, T., Miles, E., \& Sheeran, P. (2012). Dealing with feeling. Psychological Bulletin, 138, 775-808.

Weisfeld, G. E., Czilli, T., Phillips, K. A., Gall, J. A., \& Lichtman, C. M. (2003). Possible olfaction-based mechanisms in human kin recognition and inbreeding avoidance. Journal of Experimental Child Psychology, 85(3), 279-295.

Young, L., \& Saxe, R. (2011). When ignorance is no excuse. Cognition, $120,202-214$. 